\title{
INNOVACIÓN Y TRANSGRESIÓN EN EL USO DE LOS FRASEOLOGISMOS
}

E n el estudio de la lengua como objeto en perpetuo y paulatino cambio, la disciplina fraseológica proporciona un ámbito verdaderamente atractivo. Este terreno no es otro que el de la renovación constante de la lengua gracias al nacimiento de unidades fraseológicas, y el de la transgresión que cada hablante puede realizar individualmente de las formas y significados de estas unidades fijadas por el uso, cuyo estudio se realiza por medio de análisis textuales.

Antes de realizar ese estudio quisiera esbozar una breve introducción teórica sobre algunos conceptos referentes a la teoria fraseológica, pertinentes para la comprensión posterior de lo que aqui se expondrá sobre innova-

Juan Pablo Larreta Zulatequi

Universidad de Sevilla en el FR antes nombrado, no tener dos dedos de frente, no se puede en modo alguno sustituir el componente dedo por mano sin destruir el contexto fraseológico: *no tener dos manos de frente. Esta restricción de la posibilidad de sustitución paradigmática no es en modo alguno absoluta, ya que a menudo existen variantes sistemáticas dentro del corpus fraseológico, como p. e. en el FR estar hasta el pelo/la coronilla/las narices/los cojones de alguien, asi como otras variantes más expresivas si cabe.

Acerca de las transformaciones semánticas de los FR, evidentes en los ejemplos dados, resulta especialmente interesante para los casos posteriores de transgresión la posibilidad de que un FR tenga una lectura literal y otra idiomática, tambièn llamada metafórica, translaticia o figurada. Como ejemplo, hacerle el coro a alguien significa literalmente ("acompañar a un músico en su interpretación de una obra", y figuradamente ("unirse a alguien en sus opiniones (generalmente con la intención de adularle)". La lectura idiomática habitualmente se actualiza antes que la literal, según demuestran estudios psicolingüisticos sobre el tema.

La última cuestión fundamental en la definición de los FR se suscita en relación a su estructura sintáctica, pues es controvertida la conveniencia de incluir dentro de los estudios fraseológicos unidades de estructura oracional. Esta caracteristica la traigo a colación sobre todo por ser los refranes unidades conocidas por todos, incluidos los no estudiosos de la materia, que asi pueden hacerse una idea más clara de cuál puede ser el alcance de los estudios fraseológicos. En un sentido amplio, se pueden considerar FR tanto estos refranes como tambièn máximas, sentencias, etc. entre las unidades de estructura oracional.

1.2 En resumen, los FR son unidades que se caracterizan fundamentalmente por:

a) Formar grupos de palabras.

b) Ser estables y, gracias a ello, reproducibles en bloque y aprehensibles en la memoria.

c) Muy a menudo pero no siempre mostrar el rasgo semántico de la idiomaticidad o transformación semántica.

d) En un sentido amplio poseer una estructura sintáctica que puede ser tanto oracional como sintagmática. 


\section{El concepto de convención en el plano fraseológico}

2.1 Este concepto se relaciona con el denominado uso habitual, a menudo manejado en la investigación fraseológica. Este uso es el que provoca que, en un momento dado, un FR sea aceptado como tal en la comunidad lingüistica en cuestión, ya que se ha llegado a un acuerdo/convención sobre su forma y significado. Esta aceptación implica un proceso histórico de adquisición paulatina por parte de la comunidad lingüistica de unidades fraseológicas 0 , dicho de otra manera, es el camino que conduce a la forma definitiva adoptada por los FR por mor del discurso repetido, que les ha dotado de la estabilidad necesaria para ser reconocidos y usados como tales por la comunidad lingüistica, y que les introduce en el sistema o corpus fraseológico. Un FR lo es, por tanto, una vez que la convención en torno a su uso (forma y significado) queda fijada.

De este modo, la expresión salvarse por los pelos procede, según Iribarren, de la práctica de los marineros, al menos en el siglo XIX, de servirse de los pelos largos como instrumentos de enganche 0 agarradero cuando vieran peligrar su integridad en $\mathrm{e}$ mar. Esta costumbre se divulgó por medio de una carta que los astilleros de marina Manuel Calderón y Manuel Morales dirigieron al rey, que habia dado orden de que los marineros de la armada se cortasen el pelo, por lo cual éstos, según la carta, "... a cada instante vense en el inminente riesgo de poderse aogar; y no teniendo pelo por donde comunmente se faborecen asiendose de el; (...) y que le puede servir de enganche o agarradero en caso de peligrar su destino en la mar (...)." (vid. Iribarren, 1994) Este origen no tiene por supuesto ningún carácter normativo, y sólo la suerte de la expresión a partir de ese momento en que se da a conocer 0 que, de algún modo, comienza a fijarse como unidad comunicativa (en la carta), determina su supervivencia hasta hoy a partir de su paulatina adquisición y uso por parte de la comunidad, siendo la convención la que fija su forma y significado definitivos como unidad lingüistica reconocida y reconocible.

2.2 Seria absolutamente arbitrario (y falso) indicar un momento exacto a partir del cual un FR es conocido y utilizado por toda una comunidad de modo uniforme en cuanto a su forma y significado en el proceso comunicativo (de hecho ese no seria sino un estado ideal, ya que nunca todos los hablantes de una comunidad conocen todas las expresiones de su idioma, existiendo naturalmente FR más conocidos y más arraigados que otros). Pero tan cierto como estas trabas teóricas, no lo es menos el hecho de que todos conocemos la expresión antes citada, no tener dos dedos de frente, al igual que cualquier alemán conoce la expresión kaltes Blut bewahren. De modo que, aunque la convención en torno a los FR no sea un hecho que pueda medirse de manera total- mente precisa y objetiva, es en cualquier caso una realidad empiricamente comprobable.

\section{Sobre el origen de los FR}

3.1 En este camino descrito de afianzamiento de los FR (y de su formación como tales) por medio de la convención en la comunidad lingüistica, deben discutirse los conceptos de innovación y transgresión en fraseologia.

La innovación significa creación de nuevos FR y ampliación de los recursos expresivos y estilisticos en las lenguas. Las fuentes extralingüisticas en las que hallamos el origen de estos FR son muy variadas. Entre ellas puede

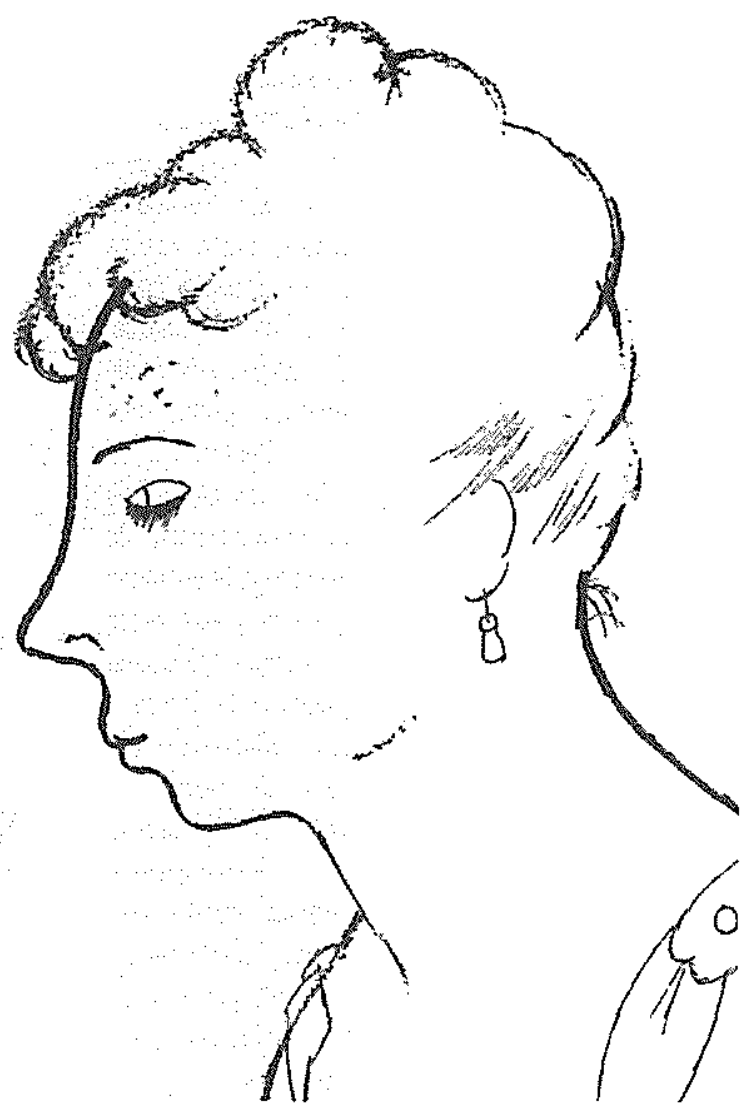
destacarse el mundo animal (aguzar los oidos, die Ohren spitzen), los avances técnicos y cientificos (a todo tren, im D-Zug durch die Kinderstube gefahren sein), la historia (llegarle a alguien su San Martin o a todo cerdo le llega su San Martin, ein Gang nach Kanossa o nach Kanossa gehen), la literatura (des Pudels Kern), o el lenguaje del cuerpo, que genera los llamados quinegramas fraseológicos (fruncir el ceño, die Stirn runzeln).

El estudio de la innovación en fraseologia reside, asi pues, en la investigación tanto de esas fuentes en las que nace esta parcela del lenguaje como del camino recorrido por el FR hasta su fijación definitiva, y termina en el instante en que la convención incorpora los FR al corpus ya fijado, momento a partir del cual pueden estudiarse los rasgos estructurales formales y semánticos de los FR sincrónica y sistemáticamente.

Habitualmente la innovación fraseológica es anónima, viva, constante y está apegada sobre todo al mundo extralingüistico más cercano al ser humano. A veces, no obstante, la innovación que supone el nacimiento de un FR tiene nombres y apellidos, pero, jatención!, en todo caso es la comunidad al adoptar la unidad en cuestión la que la convierte realmente en FR.
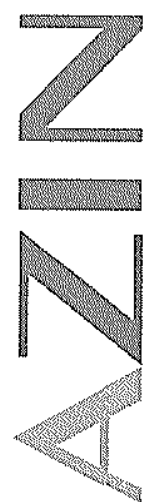
3.2 Esta innovación con nombres y apellidos pero no voluntaria (sus autores no los sienten como FR) está representada en la investigación fraseológica por una serie de FR llamados geflügelte Wörter (palabras aladas).

La historia de este término se remonta a la obra de Georg Büchmann, Geflügelte Wörter. Der Zitatenschatz des deutschen Volkes, quien realiza en su creación, como él mismo reconoce, "(...) un pequeño falseamiento periodistico (...)." Büchmann se refiere con ello a que las "épea pteróenta" de Homero, que aparecen cuarenta y seis veces en la lliada y cincuenta y ocho en la Odisea, y cuya traducción por parte de Stollberg y Voss fue "geflügelte Worte", eran realmente palabras pronunciadas por los dioses y por los hombres que alcanzaban el oido del oyente gracias a unas alas. No se entendia dentro

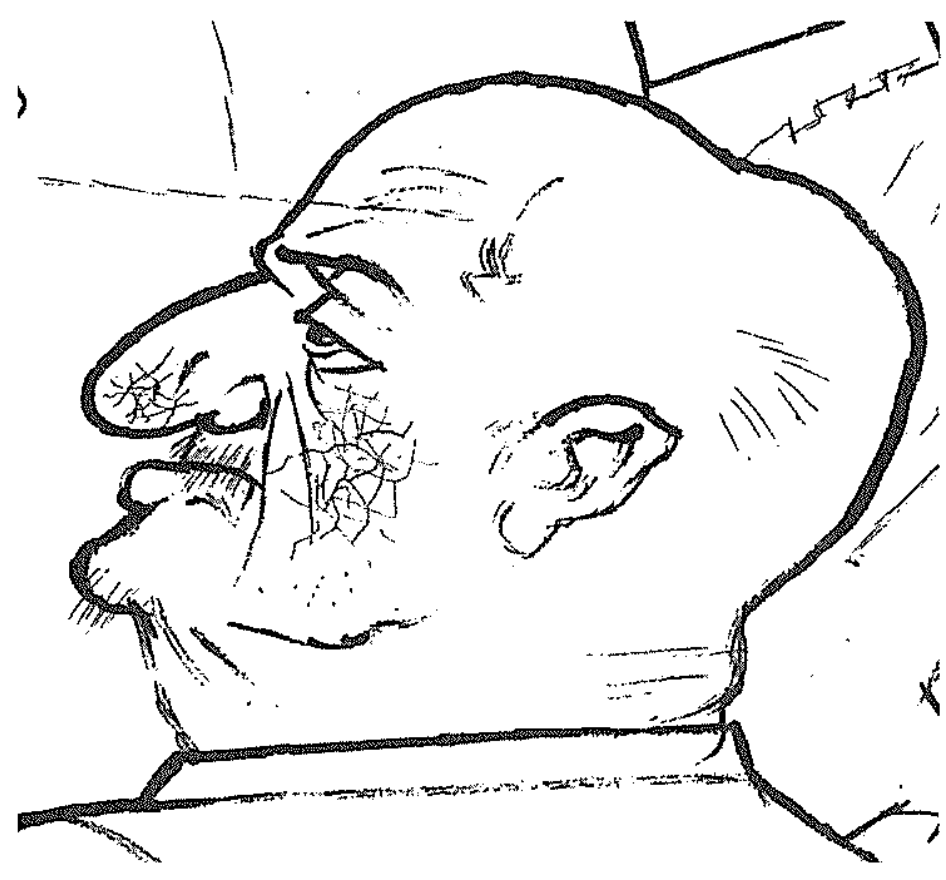

puede ser con la Iglesia hemos topado, Sancho, expresión que indica, por parte del emisor, la presencia de algún obstáculo insoslayable. La procedencia de esta palabra alada no admite dudas. Son estas unidades ejemplos de cómo a través de la literatura se generan innovaciones que pueden incorporarse a la lengua, independientemente del registro en el que se usen.

En las ediciones sucesivas de la obra de Büchmann, el autor amplia el sentido de lo literario, refirièndose a todas las fuentes documentadas y comprobables impresas (p. e. documentos históricos). Asi, interesante en este sentido es el diccionario El porqué de los dichos, de José M. Iribarren (1994), pues esta obra incluye un capitulo denominado "Expresiones afortunadas y frases históricas", que, a partir de esta nueva definición, podrian del concepto por tanto ningún tipo de generalización de dichas palabras en la comunidad lingüistica. En todo caso, Büchmann entiende por estas palabras aladas, "expresiones de uso generalizado, documentadas literariamente." (tambièn se les denomina en los estudios fraseológicos fraseologismos de autor). Vemos que las palabras aladas no se describen lingüísticamente desde una perspectiva sincrónica a través de una estructura propia, sino a través de su procedencia, y su estudio se encuadra dentro de la tradición filológica de aspectos diacrónicos1.

Ejemplos de palabras aladas son etwas riechtist faul im Staate Dänemark (Shakespeare, Hamlet), traduccion de "something is rotlen in the state of Denmark". Este es de todos modos un FR poco conocido, según he indagado entre hablantes nativos, que significa ( 'algo no está bien, no está en orden'; den Wald vor lauter Bäume nicht sehen (Wieland, Musarion), cuyo significado es ('no reconocer lo esencial para la solución de un problema debido a la existencia de múltiples detalles'. En esta expresión, según L. Röhrich, Wieland sólo ha fijado la forma exacta, que no la idea, pues ésta puede encontrarse ya en Ovidio bajo otras metáforas ("no ver las hojas en el bosque, ni la hierba en el prado ni el agua en la corriente del rio") (vid. Röhrich, 1991). Un ültimo ejemplo encuadrarse dentro de lo que se entiende por palabras aladas. Iribarren recoge abundantes expresiones afortunadas y frases históricas, tanto literarias como no, algunas tan conocidas como brillar por su ausencia, que procede de los Anales de Tácito, quien, relatando los funerales de Junia, hermana de Bruto y viuda de Casio, se refiere al hecho de que justamente faltaban los retratos de estos últimos en la comitiva religiosa, según la costumbre vigente en la época de que los retratos de los familiares acompañaran al muerto, por lo que resallaban más que ningún otro retrato presente sin estar realmente; o la expresión tempestad en un vaso de agua, introducida por Cicerón, aludiendo a las disensiones que Mario, conciudadano suyo, promovia en las elecciones municipales de la ciudad de ambos, Arpino; finalmente, un FR presente tanto en alemán como en español, estar sobre un volcán/ein Tanz auf dem Vulkan, se remonta a una frase pronunciada por el politico francés Aquiles Salvandy, en una fiesta dada el 31 de Mayo de 1830 por el Duque de Orleáns en honor de su cuñado el rey de Nápoles (la fiesta se celebraba en Nápoles). La frase fue: "Voilá une fête bien napolitaine: nous dansons sur un volcan", y en ella Salvandy aludia, a través del rey de Nápoles y el Vesubio, a la agitada actualidad politica. Efectivamente, pocos 
dias después, el 27 de Julio, estalló en Paris la primera de las revoluciones liberales.

Para Burger et al (1982), si se quiere entender el concepto de palabra alada no sólo como un fenómeno tipico de la filologia decimonónica, sino como una categoria más general que desempeñe también su papel en la lingüistica actual, debe extenderse su comprensión a un campo más amplio. De este modo, deben incluirse igualmente como fuentes de estas unidades origenes más prosaicos, ya sean impresos o no, como FR nacidos en algunos medios de comunicación, títulos de peliculas, canciones de éxito o slogans propagandisticos (vid. Burger et al. 1982: 45-47). La ampliación del campo fraseológico en este sentido es discutible, pero no me detendré en ello ahora.

3.3 Estas palabras aladas deben diferenciarse del denominado ocasionalismo, unidades cuyo estudio casi escapa del terreno de la fraseologia. El término ocasionalismo designa unidades que podrian considerarse fraseológicas (o sea, que por sus caracteristicas semánticas y formales, exceptuando la pertenencia a la comunidad dada por el uso habitual, podrian ser FR) y se hallan dentro de una obra literaria, unidas a ese texto artistico, sin convertirse en bien común de la colectividad ni representar variación alguna respecto a algún FR asentado. Estos ocasionalismos se desarrollan como tales a lo largo de la obra en cuestión, en la cual se repiten como cadena estable con significado figurado, y deben de algún modo ser introducidos como tales por el autor, que de un modo u otro debe ayudar al lector a reconocerlos asi, ya que no están presentes en la conciencia colectiva.

En estos ocasionalismos si hay una voluntariedad de innovación de la lengua por parte de su creador, al contrario que en las palabras aladas, sin que por el contrario hayan tenido la fortuna de que la comunidad y la convención les hayan dado cabida en la lengua. Algunos autores, como W. Fleischer, defienden que, en todo caso, los ocasionalismos son motivo de estudio fraseológico, aunque no lleguen a ser FR de uso habitual, para no romper la dialéctica de los conceptos de lengua y habla. Según Fleischer, si se excluyen estas construcciones ocasionales de un modo tajante delámbito de la fraseologia, se traza una linea arbitraria, antidialéctica entre lengua y habla. Para Fleischer, los ocasionalismos pueden considerarse como FR porque son construccciones ocasionales en las que se encierra una tendencia 0 potencialidad a la fijación y a la estabilidad debido a sus caracteristicas semánticas, formales y funcionales. Ejemplo de ocasionalismo es la unidad auf den Steinen sitzen, desarrollada en la novela Die Buddenbrooks de Th. Mann, donde el autor la introduce explicitamente como expresión fija:

"Es konnte nicht fehlen, daß Tony oftmals mit ihrer städtischen Bekannschaft am Strande oder im Kurgarten verkehrte, daß sie zu dieser oder jener Réunion und Segelpartie hinzugezogen wurde. Dann saß Morten 'auf den Steinen'. Diese Steine waren seit dem ersten Tage zwischen den bejden zur stehenden Redewendung geworden. 'Auf den Steinen sitzen', das bedeutete: 'Vereinsamt sein und sich langweilen'. Kam ein Regentag, der die See weit und breit in leinen grauen Schleier hüllte, daß sie völlig mit dem tiefen Himmel zusammenfloß, (...), dann sagte Tony: "Heute müssen wir auf den Steinen sitzen' ... daß heißt in der Veranda oder im Wohnzimmer." (ejemplo tomado de Fleischer, 1982).

Aunque la expresion no ha tenido fortuna y no ha
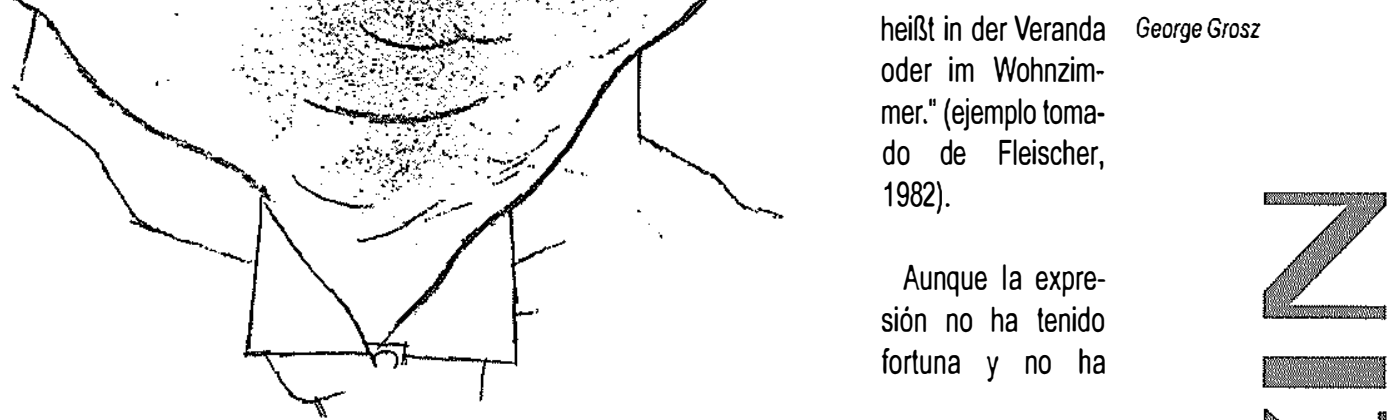

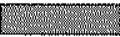


pasado ha engrosar la nómina de FR del alemán actual, y por ello permanece en la esfera del ocasionalismo, la posibilidad de ser entendida o sentida como un FR es evidente a partir de todos los indicios que da el autor para ello (dificil será encontrar un ejemplo tan claro). A la

a) declaración explicita de que se trata de una expresión si bien sólo entre dos personas ("zwischen den beiden zu einer stehenden Redewendung geworden"), debe añadirse
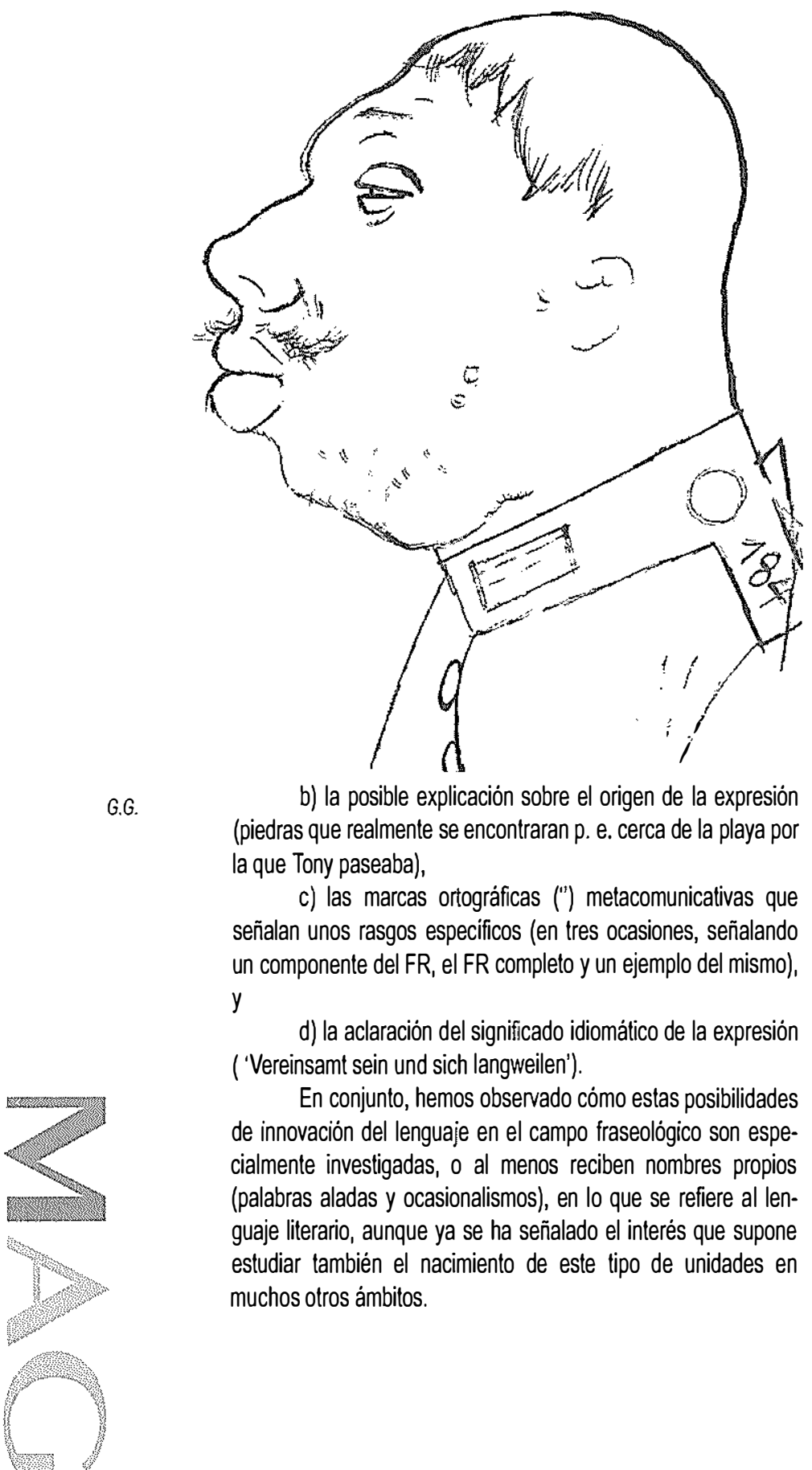

b) la posible explicación sobre el origen de la expresión (piedras que realmente se encontraran p. e. cerca de la playa por la que Tony paseaba),

c) las marcas ortográficas (") metacomunicativas que señalan unos rasgos especificos (en tres ocasiones, señalando un componente del FR, el FR completo y un ejemplo del mismo), $y$

d) la aclaración del significado idiomático de la expresión ('Vereinsamt sein und sich langweilen').

En conjunto, hemos observado cómo estas posibilidades de innovación del lenguaje en el campo fraseológico son especialmente investigadas, 0 al menos reciben nombres propios (palabras aladas y ocasionalismos), en lo que se refiere al lenguaje literario, aunque ya se ha señalado el interés que supone estudiar tambièn el nacimiento de este tipo de unidades en muchos otros ámbitos.
3.4 Contrastivamente, los ocasionalismos no ofrecen posibilidad alguna, ya que son creaciones individuales que evidentemente no pueden hallar paralelismo alguno en otra lengua. Sin embargo, las palabras aladas $y$, sobre todo, todas las demás causas que pueden originar un FR, señaladas en el punto 3.1, son especialmente interesantes.

Asi, llamativos son, por ejemplo, los FR con un origen histórico 0 socio-cultural, que a menudo dan lugar a particularismos en cada lengua, pero que muchas veces generan internacionalismos, FR presentes en varias lenguas que generalmente se desarrollan bajo un sustrato cultural comun (p. e., muchas lenguas europeas presentan similitudes en el terreno fraseológico gracias a la Biblia o a la Antigüedad Greco-latina).

Otros FR se asemejan en las diversas lenguas por pertenecer a mecanismos lingüisticos universales, como los somatismos, FR en los que algún componente refleja una parte del cuerpo humano (ser todo oidos y ganz Ohr sein), o los quinegramas fraseológicos, basados en códigos de comunicación no verbales igualmente universales (encogerse de hombros y mit den Achseln zucken).

El estudio de los particularismos también resulta muy atractivo, pues refleja rasgos autóctonos culturales muy variados, como pueden ser referidos a costumbres culinarias, leyes, sistemas de pesas y medidas, monedas, etc. En este sentido, los FR pueden ser una ayuda valiosa en la aprehensión de los temas culturales que conlleva el aprendizaje de una lengua extranjera.

\section{Transgresión individual de los FR}

4.1 Todos los casos descritos hasta ahora son mecanismos de creación de unidades lingüisticas, sancionados o no posteriormente por la normaiconvención. Pero la lengua continúa transformándose en aquellos FR que ya han quedado fijados por la norma, cuya forma y significado pueden a partir de ese momento ser transgredidos por el hablante.

Asi, transgresión existe en las denominadas variantes individuales de los FR, que modifican FR ya existentes, bien semánticamente, bien semántico-formalmente. Estas variaciones individuales no están sujetas al uso de la colectividad, y, por ello, se desvian de la norma/convención lingüistica. En ellas se transgrede la estabilidad fraseológica, rasgo considerado fundamental en la definición de los FR, ya que se parte de FR fijos y sancionados por el uso, modificándolos de un modo u otro. Son variaciones individuales ajenas a la variabilidad fraseológica sistemática, término que, como se vio con el ejemplo de estar hasta las narices/la coronilla/etc. de alguien, completa al de la estabilidad. Las variaciones individuales, modificaciones 0 desviaciones de los FR son a menudo juegos de palabras, ligados al carácter lúdico que en muchas ocasiones acompaña al uso del lenguaje. Para 
ello, las unidades lingüisticas establecidas son distorsionadas por el hablanteemisor, con la intención de llamar la atención del receptor de manera evidente. Pero también es el receptor, como veremos, el que puede contribuir a la modificación del FR.

La polilexicalidad de los FR es la que encierra esta potencialidad de modificaciones y el entrelazamiento formal $y$ conceptual del FR en el texto a partir de dichas modificaciones. Estos fenómenos recuerdan a la función poéticacreativa de la que hablaba Jakobson, que en estos casos se sitúa en un mismo nivel o un nivel superior a la función comunicativa. El juego con el lenguaje significa su dominio,

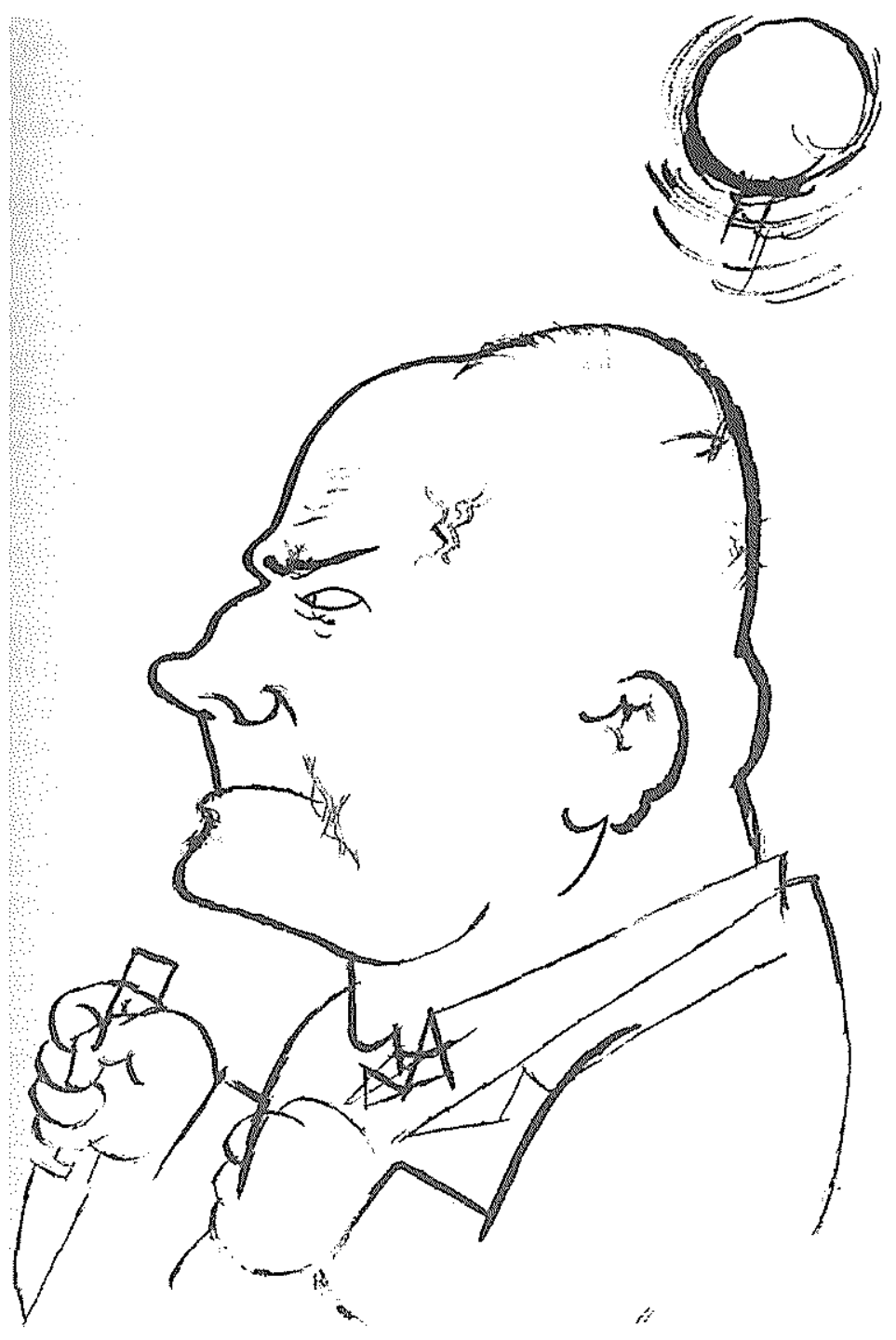

la alegria de su uso, el gusto por la observación de los mecanismos lingüisticos

Cualquier transgresión del FR mantiene, sin embargo, un contacto más o menos explicito con la llamada base fraseológica, el significado y la forma real del FR, que en cierto modo se encuentran presentes 0 coactualizados junto a la modificación efectuada, aunque sea en un segundo plano, lo cual da verdaderamente sentido a las diversas desviaciones del uso habitual. Este hecho implica que tanto la producción como la recepción de algunas de estas desviaciones o modificaciones y juegos de palabras exijan un grado de conocimiento (lingüistico y extralingüistico) previo del usuario, que a veces es realmente complejo. Un ejemplo muy adecuado es uno dado por B. Wotjak, concretamente el titulo de un reportaje sobre las actividades de espionaje de Markus Wolf, Wolf im Luchspelz. Para comprender en todo su tor falla (ya sea por desconocimiento de la base fraseológica, falta de conocimientos extralingǘsticos o excesiva complejidad conceptual de la transgresión efectuada), con lo cual no tiene lugar la participación de alguno de ellos en el uso lúdico del lenguaje, de modo que la fuerza perlocutiva de la expresión modificada se pierde, e incluso algún uso puede ser considerado como erróneo. De todos modos, hay dos medios habituales, objetivamente medibles, para evitar esta falta de comunicación:

a) Que la expresión sea "dirigida" con medios metacomunicativos.

b) Que la expresión aparezca, previamente a su modificación, en su forma normal.

En definitiva, la transgresión a la convención fraseológica implica una modificación semántica o semántico-formal de la base fraseológica, de manera que a veces pueden producirse 


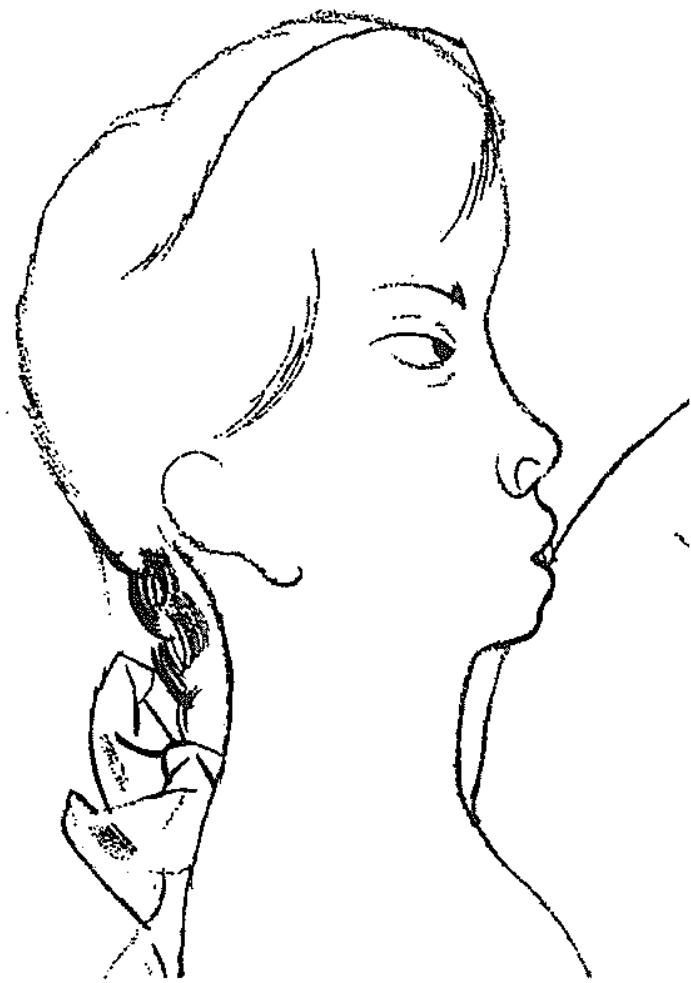

interferencias en la comunicación entre emisor y receptor, cuando no se capta por algún motivo la desviación efectuada.

A partir de ahora, y para entrar en la parte final de este articulo, voy a analizar una serie de ejemplos pertenecientes a distintos tipos de textos. Veremos en ellos distintos mecanismos de transgresión y, en caso posible, intentare descifrar el porqué del uso de estas anomalias a la regla fraseológica.

4.2 Estos usos pueden representar en primer lugar una transgresión semántico-formal. Existen varios mecanismos para realizar esta transgresión, según los medios formales que se empleen en cada caso, sin que a cada uno de estos medios se les pueda adscribir una función especifica.

a) El primer medio es la sustitución léxica, cambio de un componente de la expresión fija por otra palabra que ocupa la misma posición dentro del FR.

La sustitución léxica puede estar condicionada paradigmáticamente, esto es, los componentes sustituyente y sustituido se encuentran en una relación de sinonimia, antonimia, etc. Generalmente, este tipo de modificación no supone una alteración grave en la estructura semántica conjunta de todo el FR (al menos cuando la relación es de sinonimia) y apenas es más expresiva que la base fraseológica sobre la que se forma. Un ejemplo de esta sustitución es:
"... jedoch sind da neun weitere Fächer, und eines ist immer verzwickter als das andere, und Deutsch ist unter allen das Buch mit den meisten Siegeln. (ejemplo tomado de Barz, 1986).2

En èl, la sustitución sieben/meisten conduce simplemente a una superlativización del significado del FR, ( 'unverständlich/am unverständlichsten').

La sustitución léxica muestra a veces relación con el texto donde se incardina el FR y no un condicionamiento paradigmático de sus componentes. Un ejemplo de ello, en el que por otro lado existe una relación homofónica entre el componente sustituyente y el sustituido, es el siguiente:

"Einer der zusieht, wie alle Fälle davonschwimmen".

Éste es el titulo de un articulo sobre un abogado que hace mal su trabajo y su base fraseológica es el FR seine Felle fortschwimmen sehen, que significa ( "seine Hoffnungen zerrinen sehen"). La comprensión del juego de palabras hecho a partir de la sustitución de los componentes homófonos Fälle y Felle sólo se completa a la luz del texto donde se encuentra el FR.

A veces, la sustitución es más amplia y puede afectar no a un componente, sino a varios. Es el ejemplo del anuncio de una agencia de viajes, que, modificando el refrán wer die Wahl hat, hat die Qual en wer die Wahl hat, nimmt die Qualität, utiliza un recurso muy empleado en publicidad, consistente en contrastar el aspecto peyorativo de la base fraseológica con el positivo de la modificación.

b) En segundo lugar, un FR puede ser modificado por expansión a través sobre todo de adjetivos y adverbios, que generalmente sólo pretenden aumentar la expresividad del FR. También pueden darse, no obstante, expansiones más complejas, como el siguiente ejemplo:

\section{"Wissen ist Macht. Unwissen ist Ohnmacht"}

Éste es un anuncio de la Enciclopedia Brockhaus en Der Spiegel, en el cual se imitan las tipicas estructuras bimembres de los refranes, que reflejan tan a menudo una concepción polarizada/maniqueista del mundo.

c) Otro mecanismo es la reducción. Gracias a èl, curiosamente se resalta a menudo justamente el elemento que desaparece, que se activa debido al contexto. Asi, el contenido de un articulo, titulado "Dusche von Siemens", en el que se habla de una serie de despidos y de tendencias a la baja en las acciones de esta empresa, activa la connotación peyorativa que contiene el adjetivo ausente en el FR del titulo, "kalt". 
En otro ejemplo," 50 Jahre lang nicht vom Weg abgekommen. Und das ohne quattro", la falta del adjetivo "recht" activa sobre todo el significado literal de "Weg", Io cual coincide con los intereses del anunciante, la marca Audi, que dirige la atención sobre su terreno (auténticos caminos por donde circulan automóviles), y aprovecha la idea positiva expresada por medio del FR.

d) Existen otros métodos de transgresión, como la sustitución de un elemento verbal por otro no verbal. En estos casos, se produce una mezcla de códigos de comunicación, y parte de un FR puede ser activado en su significado literal o en el idiomático mediante una imagen. Esta mezcla de códigos merece en todo caso un trabajo aparte, por lo que evito tratar aqui ningún ejemplo.

4.3 Las modificaciones pueden constituir también únicamente una transgresión semántica.

La transgresión en este caso se basa en el doble juego de los significados literal e idiomático. Dado que los FR se utilizan en principio para ser decodificados idiomáticamente, la comprensión literal, o la coactualización de ambos significados, inducidos por el emisor o realizados intencionadamente por el receptor, puede producir muchos efectos que podrian considerarse transgresores de la norma, ya que el FR no transmite el mensaje que en principio deberia segün la convención en torno a su significado idiomático.

La coactualización de ambos significados, literal e idiomático, se produce de varios modos (detenidamente en B. Wotjak, 1992), ya que a veces se actualiza uno con más fuerza o claridad que el otro, o de manera no simultánea, como podemos observar en algunos ejemplos:

a) Puede actualizarse el significado idiomático en primer lugar y a continuación el significado literal de algún componente del FR:

"Der Film brachte manch einen Kritiker auf die Palme, wobei auch mir dieser Hochsitz sehr angemessen erscheint".

b) Se puede dar también una actualización del significado literal junto al cual el homónimo idiomático se vislumbra:

"Es sei bemerkt, daß die Frauen nach wie vor die Hosen anhaben. Meist Modelle, die legere Oberschenkelweiten aufweisen".

Este ejemplo es un tanto polémico, ya que en principio lo normal es activar el significado idiomático. Pero la segunda oración obliga a la actualización del significado literal. En cualquier caso, como decia, el idiomático se vislumbra.

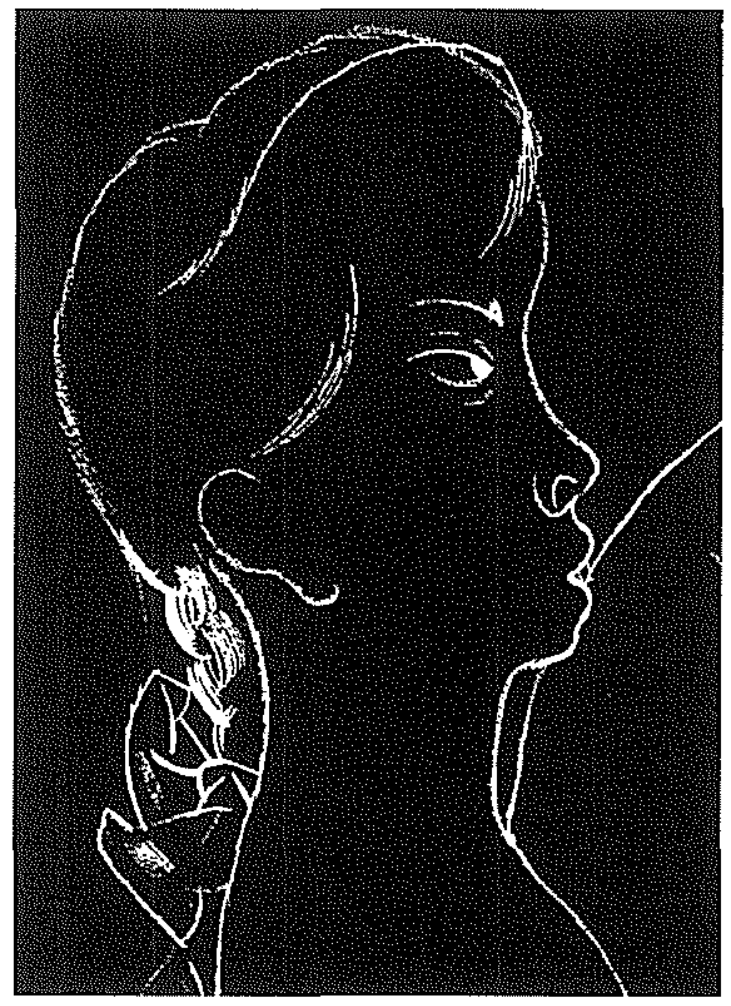

c) Igualmente pueden actualizarse en su totalidad ambos significados, aunque uno puede preceder a otro. En un primer ejemplo se advierte una actualización previa del significado idiomático:

"Und da wandte sich das schöne, blonde Mädchen an den riesigen, brutal aussehenden, blutbefleckten Mann, der, ein blinkendes Messer in der Hand, erbarmungslos auf sie blickte.

"Haben Sie denn kein Herr?"

"Nein", sagt er ungerührt.

"Ach", seufzte sie, "dann geben Sie mir eben 300 Gramm Leber!"

$Y$ en un segundo ejemplo se observa una actualización previa del significado literal:

Conversación de Mariano Rubio con un empleado de una agencia de viajes:

-"Dadas mis circunstancias actuales, recomiéndeme una isla para pasar mis vacaciones.

-¿Cuáles son sus preferencias?

- Me gusta estar a la sombra.

¿¿Qué le parece Alcatraz?" 
Éstos son algunos posibles tipos de transgresión que efectúa el emisor. Pero también es posible que sea el receptor quien voluntariamente transgrede la convención. Eso es lo que hace Humpty Dumpty, personaje de Alicia en el pais de las maravillas, quien rompe en su conversación con Alicia la convención lingüistica, ignorando a propósito el significado idiomático del FR I beg your pardon:

"I beg your pardon?" Alice said with a puzzled air.

"I'm not offended," said Humpty Dumpty.

"I mean, what is ..."

El lenguaje y sus convenciones son destrozados por la esencia del pais de las maravillas, especialmente por Humpty Dumpty. El FR deja de funcionar como tal (con su significado idiomático) dado que el receptor obvia entenderlo.

4.4 Desde un punto de vista contrastivo, es muy dificil realizar un análisis de estas transgresiones a la norma, dado que éstas son, como se ha dicho, individuales. Seguramente no tendrá sentido intentarlo en el caso de las transgresiones semánticas que hemos visto en último lugar. No obstante, en el caso de las transgresiones semántico-formales, podria acometerse un estudio sobre qué tipos de mecanismos formales predominan en cada lengua, en el caso de que ello fuera realmente asi. En cualquier caso, para llegar a posibles conclusiones habria que trabajar con un amplisimo número de ejemplos, y relacionar tal vez dichas conclusiones con determinados rasgos generales morfosintácticos y léxicos de los corpora de ambas lenguas.

Si creo que seria sin duda productivo e interesante el manejo de este tipo de material como instrumento didáctico en clases de lengua a partir de un nivel bastante elevado, fundamentalmente por tres razones: a) En primer lugar, por el atractivo que pueda suponer para el estudiante este tipo de material, con lo que puede contribuir a aumentar la motivación del mismo.

b) Por la refexión metalingüistica a la que obliga, 0 , al menos, que es susceptible de despertar.

c) Por introducirse en un nivel que implica el aprendizaje de mecanismos semánticos complejos de la lengua en cuestión.

J.P.L.Z. $\sim$

\section{Bibliografia}

-Barz, I. (1986): "Probleme der phraseologischen Modifikation", en Deutsch als Fremdsprache, 23, 321-326.

-Burger, H./Buhofer, A./Sialm, A. (1982): Handbuch der Phraseologie, Walter de Gruyter, Berlin/New York.

-Fleischer, W. (1982): Phraseologie der deutschen Gegenwartsprache, VEB Bibliographisches Institut Leipzig, Leipzig

-Inibarsen, J. L. (1994): El porqué de los dichos. Sentido, origen y anécdota de los dichos, modismos y frases proverbiales de España con otras muchas curiosidades, Gobierno de Navarra, Opto. de Educación y Cultura, Pamplona, $7^{\mathrm{a}}$ ed.

-Röhrich, L. (1991): Das große Lexikon der sprichwörttichen Redensarten, Herder, Freiburg i. B.Basel/Wien. 


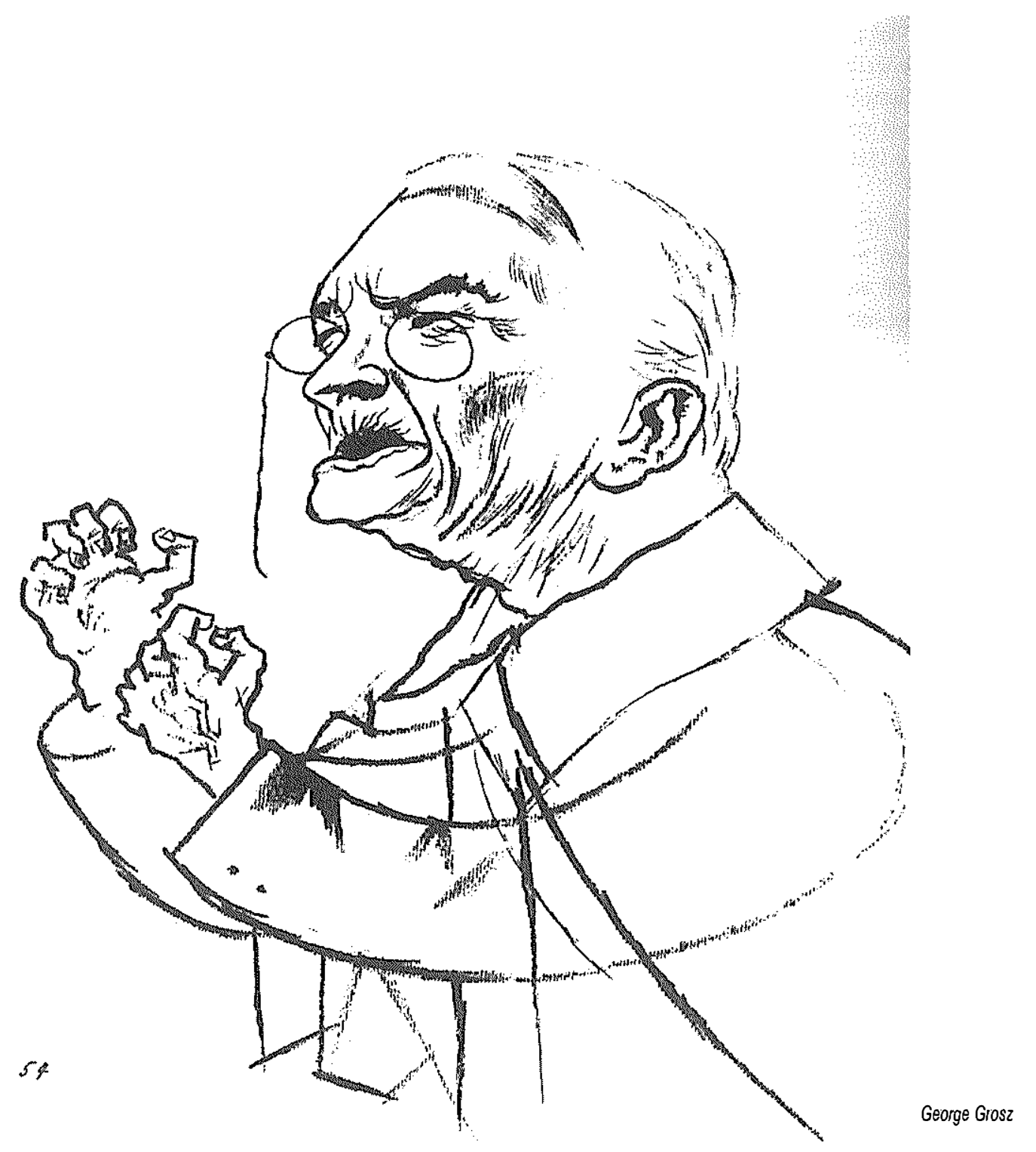

-Wotjak, B. (1992): Verbaie Phraseolexeme in System und Text, Niemeyer, Tübingen (Reihe Germanistische Linguistik, 125).

\section{Notas}

1 Todos estos datos sobre el origen de este concepto los he tomado de Burger et al., 1982: 43-56.

2 A excepción de este ejemplo y del último, todos los demás han sido tomados del trabajo de B. Wotjak que se refleja en la bibliografia, de la revista El Jueves o del número especial de la revista Der Spiegel que conmemora su cincuentenario.
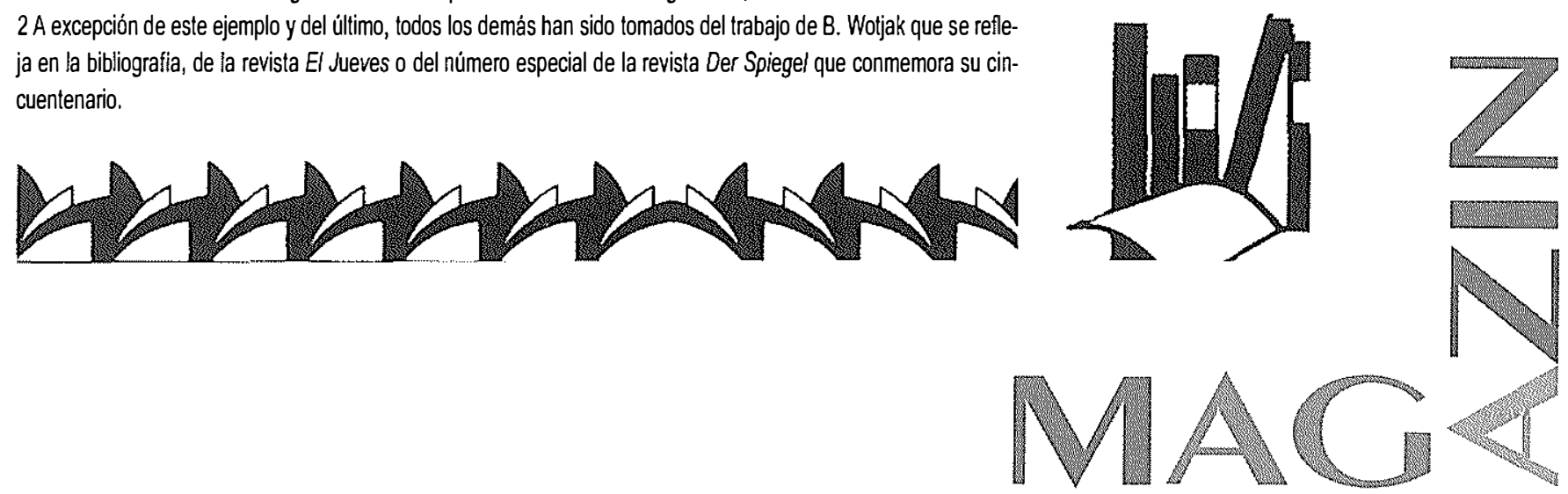